\title{
Effects of astragalus polysaccharide on the adhesion-related Immune response of endothelial cells stimulated with CSFV in vitro
}

\author{
Zengyu Zhuge ${ }^{1}$, Yanpeng Dong ${ }^{2}$, Liuan Li ${ }^{1}$, Tianming Jin ${ }^{\text {Corresp. } 1}$ \\ ${ }^{1}$ Animal Science and Veterinary Medicine College, Tianjin Agricultural University, Tianjin, Tianjin, China \\ 2 College of Forestry, Henan Agricultural University, Zhengzhou, Henan, China \\ Corresponding Author: Tianming Jin \\ Email address: jtmsci@163.com
}

Background: Astragalus polysaccharide (APS) has immunomodulatory activities on porcine peripheral blood mononuclear cells. The immunomodulatory effects of APS on porcine endothelial cells (ECS) expose to classical swine fever virus (CSFV) remain unknown.

Methods: The virus was titrated using an indirect immune biotin enzyme standard method to confirm that porcine ECs were susceptible to CSFV infection and to determine the TCID50 of CSFV (C-strain). Porcine ECs were cultured with CSFV in the presence of APS. Relative quantitative PCR was used to assess the mRNA expression of factors that influence EC adhesion and immunity.

Results: The expression of adhesion factors mRNA increased following stimulation with CSFV; this effect was inhibited by pre-exposing the cells to APS. In addition, the expression of growth factors and some immune factors increased after infection with CSFV; this increase in tissue factor (TF), transforming growth factor (TGF- $\beta$ ), and interleukin-8 (IL-8) could be inhibited by the addition of APS. The immune response mediated by Toll-like receptor 4 (TLR4) in ECs may be unregulated by CSFV as it was also inhibited by pre-treatment with APS.

Discussion: The addition of APS to the culture can obviously regulate the expression of molecules related to the adhesion, growth, and immune response of ECs, as well as the production of cytokines. Therefore, it may have the potential to be an effective component in vaccines against CSFV. 
$6{ }^{1}$ Animal Science and Veterinary Medicine College, Tianjin Agricultural University

722 Jinjing Road, Tianjin 300384, China

$8{ }^{2}$ College of Forestry, Henan Agricultural University, 95 Wenhua Road, Zhengzhou 450002,

9 China

10

11 *The First author: Zengyu Zhuge

$12{ }^{\dagger}$ Corrsponding author: Tianming Jin

13 E-mail: jtm680@163.com 


\section{Abstract}

15 Background: Astragalus polysaccharide (APS) has immunomodulatory activities on porcine

16 peripheral blood mononuclear cells. The immunomodulatory effects of APS on porcine

17 endothelial cells (ECs) expose to classical swine fever virus (CSFV) remain unknown.

18 Methods: The virus was titrated using an indirect immune biotin enzyme standard method to

19 confirm that porcine ECs were susceptible to CSFV infection and to determine the TCID50 of

20 CSFV (C-strain). Porcine ECs were cultured with CSFV in the presence of APS. Relative

21 quantitative PCR was used to assess the mRNA expression of factors that influence EC adhesion

22 and immunity.

23 Results: The expression of adhesion factors mRNA increased following stimulation with CSFV;

24 this effect was inhibited by pre-exposing the cells to APS. In addition, the expression of growth

25 factors and some immune factors increased after infection with CSFV; this increase in tissue

26 factor (TF), transforming growth factor (TGF- $\beta$ ), and interleukin-8 (IL-8) could be inhibited by

27 the addition of APS. The immune response mediated by Toll-like receptor 4 (TLR4) in ECs may

28 be unregulated by CSFV as it was also inhibited by pre-treatment with APS.

29 Discussion: The addition of APS to the culture can obviously regulate the expression of

30 molecules related to the adhesion, growth, and immune response of ECs, as well as the

31 production of cytokines. Therefore, it may have the potential to be an effective component in

32 vaccines against CSFV.

Introduction

35 Classical swine fever (CSF) is a highly contagious disease affecting swine and leads to 
36 tremendous economic losses worldwide. The virus of CSF (CSFV) is a member of the Pestivirus

37 genus of the Flaviviridae family, which also includes viruses that cause bovine viral

38 diarrhea/mucosal disease and border disease. ${ }^{1}$

39 A CSFV infection in pigs causes hemorrhagic disease characterized by disseminated

40 intravascular coagulation, thrombocytopenia, and immunosuppression. ${ }^{2}$ Many different cell types

41 have been studied in investigations of CSFV including macrophages. ${ }^{3,4}$ Vascular endothelial cells

42 (ECs) maintain a hemostatic balance by providing a quiescent, anti-thrombotic barrier. ${ }^{5}$ ECs can

43 be infected by CSFV and finally induces vascular diffuse lesions in the host. ${ }^{6,7}$ However, ECs can

44 be rapidly activated by pathogens to express a proinflammatory and procoagulant phenotype to

45 eliminate infection. ${ }^{8}$ Evidence supports the notion that ECs play a critical role in the recruitment

46 of immune cells, as well as influencing the outcome of the immune response. ${ }^{9,10,11}$

47 Some factors can modulate EC function, including vascular endothelial growth factor

48 (VEGF), VEGF is a multifunctional cytokine that plays a critical role in the regulation of

49 angiogenesis and is also a potent mitogen that specifically targets ECs. ${ }^{12}$. The activation of tissue

50 factor (TF) may regulate the initiation of the coagulation protease cascade in various cellular

51 settings ${ }^{13}$ and is essential for triggering angiogenesis via VEGF production by human fibroblasts. ${ }^{14}$

52 Cell adhesion molecules (CAMs) including P-selectin and E-selectin, which are involved in

53 cell tropism and pathogenesis during the course of viral infections. ${ }^{15}$ The expression of tumor

54 necrosis factor (TNF)- $\alpha$ may contribute to the leukopenia in pigs infected with CSFV by

55 promoting apoptosis. ${ }^{16} \mathrm{CSFV}$ induces proinflammatory cytokines and tissue factor (TF)

56 expression and inhibits apoptosis and interferon synthesis during the infection of porcine vascular

57 ECs: The virus infection inhibited polyinosinic-polycytidylic acid [poly(I:C)]-induced $\alpha / \beta$ IFN 
58 (type I IFN) synthesis and there was a 100-fold increased capacity to resist apoptosis induced by

59 poly(I:C) when the porcine kidney cell line SK-6 was infected with CSFV. ${ }^{10}$ Type I IFNs have a

60 bifunctional role in limiting the spread of the virus and inducing an antiviral state in uninfected

61 cells while promoting apoptosis in infected cells. Furthermore, virus-induced apoptosis can be

62 inhibited by anti-IFN- $\alpha / \beta$ antibodies. ${ }^{17}$

63 Endothelial-to-mesenchymal transition (EMT) contributes to fibrosis, which is a major cause

64 of human death and disability. ${ }^{18,} 19$ The progression of fibrosis due to aortic banding is associated

65 with the increased expression of mRNA encoding transforming growth factor- $\beta 1$ (TGF- $\beta 1) .{ }^{20}$

66 Astragalus polysaccharide (APS), which have been identified as an acidic

67 heteropolysaccharide mainly composed of glucose, galactose, arabinose, rhamnose and small

68 amount of mannose, fructose, ribose, xylose, fucose, glucuronic acid, and galacturonic acid, is

69 extracted from Astragalus membranaceus (AM) roots and generally purified by dissolving in the

70 distilled water, dialysis and lyophilization. ${ }^{21}$ APS is the main active ingredient in AM with

71 molecular weights in the range of $8.7 \times 10^{3}-4.8 \times 10^{7} \mathrm{~g} \mathrm{~mol}^{-1},{ }^{22}$ has a substantial effect on

72 exerting immunomodulatory effects in macrophage cells, ${ }^{23}$ activating the immune system by

73 clearing immune complexes, ${ }^{24}$ enhancing the transformation of $\mathrm{T}$ lymphocytes, as well as

74 activating B lymphocytes and dendritic cells (DC). ${ }^{25,}{ }^{26}$ Moreover, APS has been used as an

75 immunomodulator for the vaccination of pigs and to enhance the protective efficacy against foot-

76 and-mouth disease virus (FMDV). ${ }^{27}$ Orally administered APS has also been shown to

77 significantly enhance the efficacy of FMDV vaccination and has important implications for the

78 further use of APS as a novel adjuvant. ${ }^{28}$ Moreover, it was reported that AM markedly attenuated

79 the inhibition of vasorelaxation and downregulation of cGMP levels in ECs, and APS exhibited a 
80 tendency to reverse both depressive responses..$^{29}$ Furthermore, APS plays a role in attenuating the

81 infiltration of inflammatory cells (e.g., neutrophils and monocytes) by decreasing the expression

82 of adhesion molecules, the release of chemokines, and induction of enzymes. ${ }^{30}$ Some of the genes

83 altered by APS treatment are associated with the activation of the immune proinflammatory

84 response, such as the promotion of interleukin-1, 8, and interferon- $\gamma$ production. Thus, APS

85 serves to improve immune defense functions while resisting the invasion of external pathogens. ${ }^{31}$

86 In our previous study, we found that APS exhibited immunomodulatory effects on cells

87 exposed to CSFV and had the potential to be an effective adjuvant in vaccines against CSFV. ${ }^{32}$ In

88 the present study, we evaluated the effect of APS on the cellular responses following a CSFV

89 with the aim of identifying a potential method of combating this hemorrhagic infection.

90

91 Materials and Methods

92 Astragalus polysaccharides and virus

93 APS (Freeze-dried) was kindly provided by Dr. Fenghua Liu (Beijing University of

94 Agriculture, Beijing, China) and stored at room temperature. A rabbit propagated C-strain of

95 CSFV was kindly provided by Dr. Hongwu Lang (China Institute of Veterinary Drug Control,

96 Beijing, China) and stored at $-20^{\circ} \mathrm{C}$.

97 Virus titration by an indirect immune biotin enzyme standard method 
98 Porcine hip artery endothelial cells (ECs) were purchased from the China Institute of

99 Veterinary Drug Control in Beijing. ECs $\left(1 \times 10^{5} / \mathrm{mL}\right)$ were incubated in M199 culture medium

100 (Invitrogen, Carlsbad, CA, USA) containing $2 \mathrm{mM}$ L-glutamine enriched with $100 \mathrm{U} / \mathrm{ml}$

101 penicillin/streptomycin (Sigma, St. Louis, MO) and 10\% heat-inactivated fetal calf serum. These

102 were incubated in a 96-well microplate $(160 \mu \mathrm{L} /$ well $)$ for $24 \mathrm{~h}\left(5 \% \mathrm{CO}_{2}, 37^{\circ} \mathrm{C}\right)$. The $\mathrm{CSFV}$ stock

103 was diluted 10 -fold $\times 10$ (from $5 \mathrm{mg} / \mathrm{mL}$ to $5 \times 10^{-10} \mathrm{mg} / \mathrm{mL}$ ), and added to the microplate at 40

$104 \mu \mathrm{L} /$ well, with each concentration occupying eight wells. After $48 \mathrm{~h}$ incubation $\left(5 \% \mathrm{CO}_{2}, 37^{\circ} \mathrm{C}\right)$,

105 the culture medium was aspirated and the plate was washed with PBS.

106 Hyperimmune rabbit-anti-CSFV serum (China Institute of Veterinary Drug Control, Beijing)

107 was inactivated at $56^{\circ} \mathrm{C}$ for $30 \mathrm{~min}$ before adding it to the culture plate $(1: 400)$ at $37^{\circ} \mathrm{C}$. The

108 plates were washed with PBS three times after $1 \mathrm{~h}$. Biotin-labeled sheep anti-swine antibodies

109 (China Institute of Veterinary Drug Control, Beijing) were added to the culture plate $(20 \mu \mathrm{g} / \mathrm{mL}$,

$110100 \mu \mathrm{L} /$ well) at $37^{\circ} \mathrm{C}$. Horseradish peroxidase-labeled avidin-biotin-peroxide complex (ABC)

$111(5 \mathrm{mg} / \mathrm{mL})$ was added $(100 \mu \mathrm{L} /$ well $)$ after $1 \mathrm{~h}$. The culture plates were washed with PBS three

112 times after 30 min. 3,3N-Diaminobenzidine Tetrahydrochloride (China Institute of Veterinary

113 Drug Control, Beijing) was added (50 $\mathrm{LL} /$ well) to develop the color. 
115 ECs were cultured in M199 culture medium in $25 \mathrm{~cm}^{2}$ culture dishes. A final concentration of

$11610^{3} \mathrm{TCID}_{50} / \mathrm{mL}$ CSFV or $10 \mu \mathrm{g} / \mathrm{mL}$ APS was added after $48 \mathrm{~h}$ subculturing. Cells were allocated

117 to one of six groups (each group had three replicates): (1) Medium (cells cultured only in

118 medium); (2) APS pre-treatment (APS added $24 \mathrm{~h}$ after subculturing); (3) APS (APS added $48 \mathrm{~h}$

119 after subculturing); (4) CSFV (CSFV added $48 \mathrm{~h}$ after subculturing); (5) CSFV + APS pre-

120 treatment (APS added $24 \mathrm{~h}$ and CSFV added $48 \mathrm{~h}$ after subculturing); (6) CSFV + APS (CSFV

121 and APS both added $48 \mathrm{~h}$ after subculturing). The cells and supernatants in each of the six groups

122 were harvested at $3 \mathrm{~h}$ and $6 \mathrm{~h}$ after the addition of CSFV (48 $\mathrm{h}$ after subculturing).

\section{RNA isolation and reverse transcription}

124 Trizol reagent (Invitrogen, Carlsbad, CA, USA) was used to extract the total RNA from the

125 ECs, and the extracted RNA was dissolved in RNase-free water (Qiagen, Valencia, CA, USA).

126 The integrity of each RNA sample was ascertained by agarose gel electrophoresis. The RNA

127 purity (OD260/OD280 absorption ratio > 1.9) and its quantity were determined and verified using

128 a NanoDrop ${ }^{\circledR}$ ND-2000C Spectrophotometer (NanoDrop Technologies Inc., Wilmington, DE,

129 USA).

130 The reverse transcription (RT) reaction was initiated by adding $2 \mu \mathrm{g}$ of total RNA and $0.5 \mu \mathrm{g}$

131 of oligo $\left(\mathrm{dT}_{15}\right)$ to $12.5 \mu \mathrm{L}$ of sterile, distilled water and heated to $72^{\circ} \mathrm{C}$ for $5 \mathrm{~min}$. After cooling

132 the samples on ice, $10 \mathrm{mM}$ dithiothreitol (DTT), $0.5 \mathrm{mM}$ of each dNTP, $5 \times$ first strand buffer

133 and 200 U Superscript II RNase H-Reverse Transcriptase (Promega, Madison, WI, USA) was

134 added. The mixture was stabilized at $25^{\circ} \mathrm{C}$ for $10 \mathrm{~min}$ and subsequently incubated at $42^{\circ} \mathrm{C}$ for 60 
$135 \mathrm{~min}$ for the RT reaction. Thereafter, the temperature was raised to $70^{\circ} \mathrm{C}$ for 15 min to inactivate

136 the reverse transcriptase. The synthesized cDNA was stored at $-20^{\circ} \mathrm{C}$ until use.

\section{Quantitative real-time PCR}

138 Quantitative real-time PCR was performed in a $20 \mu \mathrm{L}$ PCR reaction containing a final

139 concentration of $10 \mu \mathrm{L} 2 \times \mathrm{SYBR}$ Premix DimerEraser and $0.4 \mu \mathrm{L}$ ROX (passive reference dye)

140 (Promega, Madison, WI, USA), $2 \mu \mathrm{L}$ of cDNA of each sample, and $0.5 \mu \mathrm{M}$ each of the forward

141 and reverse primers. The thermal cycling profile consisted of four steps: (1) denaturation at $95^{\circ} \mathrm{C}$

142 for $30 \mathrm{~s}$; (2) amplification for 45 cycles of denaturation at $95^{\circ} \mathrm{C}$ for $5 \mathrm{~s}$, annealing at $55^{\circ} \mathrm{C}$ for 30

$143 \mathrm{~s}$, and extension at $72^{\circ} \mathrm{C}$ for $1 \mathrm{~min}$; (3) melting curve by $95^{\circ} \mathrm{C}$ for $15 \mathrm{~s}, 60^{\circ} \mathrm{C}$ for $1 \mathrm{~min}$, and $95^{\circ} \mathrm{C}$

144 for $30 \mathrm{~s}$; and (4) cooling at $4^{\circ} \mathrm{C}$. All reactions were conducted in triplicate using a 7500 Real-

145 Time PCR System (Applied Biosystems, Foster City, CA, USA). A non-template nuclease-free

146 water control was included for each run. The primers (Applied Biosystems, Foster City, CA,

147 USA) for P-selectin, E-selectin, VEGF, TF, TLR4, IFN- $\alpha, \beta, \gamma, \mathrm{IL}-1,6$, 8, and hypoxanthine

148 phosphoribosyl-transferase (HPRT) are listed in Table 1. SyBgreen Gene Expression Assays

149 (Promega, Madison, WI, USA) were used in our study. To evaluate the relative quantification of

150 cDNA, the cycle threshold $(\mathrm{Ct})$ value of the target genes for each sample were determined and

151 normalized to the Ct-values of the housekeeping gene, HPRT. The results were presented as the

152 fold change using the $2^{-\Delta \Delta \mathrm{Ct}}$ method. 
153

154

155

156

157

158

159

160

161

162

163

164

165

166

167

168

169

170

171

172

\title{
Protein quantification by ELISA
}

\author{
The concentration of IFN- $\alpha$, IFN- $\gamma$, and TGF- $\beta$ in the cell culture supernatants was assayed
} according to the manufacturer instructions of commercial ELISA kits (R\&D Systems, Minneapolis, MN, USA).

\section{Statistical analysis}

SPSS software was used for all statistical evaluations (SPSS Version 16.0, SPSS Inc., Chicago, Illinois, IL, USA). A one-way analysis of variance (ANOVA) was used to test for differences between the groups, and the data were analyzed via a non-parametric Dunnett's test. The results are presented as the means \pm SEM. $P$-values less than 0.05 were considered to be statistically significant.

\section{Results}

\section{TCID $_{50}$ of CSFV}

Puce cytoplasm reveals which ECs were infected with CSFV (Figure 1). The results are expressed as $50 \%$ of the tissue culture infective dose $\left(\mathrm{TCID}_{50}\right): 10^{3} \mathrm{TCID}_{50} / \mathrm{mL}$ is equivalent to $10 \mu \mathrm{g} / \mathrm{mL}$ of the CSFV C-strain.

mRNA expression of E-selectin, P-selectin, VEGF, TF, TLR-4, IFN- $\alpha$, IFN- $\beta$ and IL-1, 6, and 8 on ECs following infection with CSFV in the presence or absence of APS

Compared with medium alone (Figure 2A), the mRNA expression of E-selectin was significantly increased $3 \mathrm{~h}$ after stimulation with CSFV in Group $4(P=0.043)$ and was even higher in Group $6(P<0.001)$. After $6 \mathrm{~h}$ of stimulation, the mRNA expression of E-selectin 
173 decreased in Group $3(P<0.001)$ but increased in Group $5(P<0.010)$.

174 After $3 \mathrm{~h}$ of stimulation with CSFV (Figure 2B), a significant decrease in the mRNA

175 expression of $\mathrm{P}$-selectin $(P=0.001)$ compared to medium alone was detected in Groups 2 and 3 ,

176 which were treated with APS. At $6 \mathrm{~h}$ post-stimulation, the mRNA expression of P-selectin was

177 significantly increased in the groups stimulated with CSFV (Groups 4, 5, and 6) compared with

178 groups that were not stimulated with CSFV (Groups 1, 2, and 3) $(P<0.010)$. The expression of

179 P-selectin was lower after stimulation with CSFV plus pretreatment with APS compared with the

180 group stimulated with CSFV alone $(P<0.001)$, whereas the expression was higher after

181 stimulation with both CSFV and APS simultaneously $(P<0.001)$.

182 VEGF mRNA expression in the ECs (Figure 2C) was higher in the presence of APS $(P=$

$1830.010)$ or CSFV $(P=0.025)$ alone but decreased in the presence of both CSFV and APS

184 compared to the medium alone at $3 \mathrm{~h}$ post-stimulation. Moreover, the mRNA expression of

185 VEGF was higher following stimulation with CSFV after pretreatment with APS compared to

186 all the other test groups $(P=0.001)$. After $6 \mathrm{~h}$ of stimulation, VEGF mRNA expression was

187 significantly increased in all stimulated groups compared to the medium alone $(P<0.001)$.

188 VEGF mRNA expression was higher in the presence of CSFV plus APS (Groups 5 and 6) than

189 in the presence of CSFV alone $(P<0.050)$. In addition, the expression of VEGF mRNA was

190 higher in the presence of CSFV following pretreatment with APS than in the group

191 simultaneously treated with CSFV and APS $(P<0.001)$.

192 After $3 \mathrm{~h}$ of stimulation, the expression of TF mRNA (Figure 2D) was higher in the 193 presence of APS alone compared to APS pre-treatment alone $(\mathrm{P}=0.005)$; TF mRNA expression 194 in the ECs was significantly increased in the presence of CSFV $(\mathrm{P} \leq 0.010)$. After $6 \mathrm{~h}$ of 
195 stimulation, TF expression was higher following APS pre-treatment alone than in the presence

196 of APS alone $(\mathrm{P}=0.018)$. TF mRNA expression was increased in the presence of CSFV alone

$197(P=0.001)$ but not following CSFV plus APS.

198 TLR4 mRNA expression (Figure 3A) in the ECs was significantly increased in the presence

199 of CSFV $(P<0.010)$ but not in the presence of CSFV plus APS pre-treatment after $3 \mathrm{~h}$ of

200 stimulation. However, TLR4 mRNA expression in the ECs was significantly increased in the

201 presence of CSFV plus APS when administered simultaneously (Group 6) $(P<0.010)$, which

202 was higher than in the presence of CSFV alone $(P=0.016)$. At 6 h post-stimulation, the mRNA

203 expression of TLR4 was significantly increased in the presence of APS alone $(P<0.001)$

204 compared to the medium controls.

205 At $3 \mathrm{~h}$ post-stimulation, the expression of IFN- $\alpha$ mRNA increased (Figure $3 \mathrm{~B}$ ) in the 206 presence of APS alone $(P=0.050)$ and CSFV alone $(P=0.006)$. At $6 \mathrm{~h}$ post-stimulation, the 207 mRNA expression of IFN- $\alpha$ was increased in Groups 2 and $5(P<0.001)$. At 3 h after 208 stimulation, IFN- $\beta$ mRNA expression (Figure 3C) was lower in the presence of APS $(P=0.026)$ 209 or CSFV alone $(P=0.016)$ than in medium control group; however, it was higher in the presence 210 of CSFV pretreated with APS $(P=0.050)$. At $6 \mathrm{~h}$ after stimulation, IFN- $\beta$ mRNA was decreased 211 in the majority of the groups except for Group 2 compared to the medium alone.

212 At $3 \mathrm{~h}$ after stimulation, the mRNA expression of IL-1 (Figure $3 \mathrm{D}$ ) was increased in Group $2133(P=0.012), 4(P=0.005), 5(P=0.001)$, and $6(P=0.009)$. At $6 \mathrm{~h}$ post-stimulation, IL-1 214 mRNA expression was only increased in the presence of APS alone $(P<0.001)$.

215 Compared to the medium control at $3 \mathrm{~h}$ after stimulation, IL-6 mRNA expression (Figure 3E)

216 was decreased in the ECs pretreated with APS $(P=0.026)$, while it increased in the presence of 
217 APS alone $(P=0.033)$. At $6 \mathrm{~h}$ after stimulation, IL-6 mRNA expression was increased in

218 Groups 2 and 3, in which APS was added at different times $(P<0.050)$. IL-6 mRNA expression

219 was significantly increased in the presence of CSFV pretreated with APS $(P=0.008)$.

220 At $3 \mathrm{~h}$ after stimulation, the expression of IL-8 mRNA (Figure 3F) was significantly

221 increased in Groups 3 and $4(P=0.002)$ and was increased in the group simultaneously treated

222 with CSFV plus APS (Groups 5 and 6) $(P=0.001)$. At $6 \mathrm{~h}$ after stimulation, IL-8 mRNA

223 expression was significantly increased in Groups $3(P=0.001)$ and $4(P=0.030)$. IL-8 mRNA

224 expression was much lower in the presence of CSFV plus APS (Group 6) than in the presence of

225 CSFV alone $(P=0.043)$.

226

227

Cytokine production following CSFV is modulated in ECs treated with APS

IFN- $\alpha$ expression in the EC supernatants was increased in all the stimulated groups (Groups

2, 3, 4, 5 and 6; Figure 4A); particularly following stimulation with APS (Groups 2 and 3). The

expression of IFN- $\alpha$ was significantly increased after stimulation with CSFV but was lower in the

presence of CSFV plus APS (Groups 5 and 6). Moreover, IFN- $\alpha$ expression was lower in the

presence simultaneously of CSFV plus APS than in the presence of CSFV following pretreatment with APS.

234 IFN- $\gamma$ expression in the EC supernatants was increased in the presence of APS alone but

235 decreased significantly in the presence of CSFV (Groups 4, 5 and 6; Figure 4B). In addition, IFN-

$236 \gamma$ expression was much lower following stimulation with CSFV plus APS (Groups 5 and 6)

237 compared to the presence of CSFV alone and was the lowest in the presence of CSFV following 238 pre-treatment with APS. 
239 TGF- $\beta$ expression (Figure 4C) in the EC culture supernatants was increased in the presence

240 of APS alone, CSFV alone, and CSFV plus APS, but decreased in the presence of CSFV

241 following pretreatment with APS.

242

243 Discussion

244 CSFV infection induced a functional decrease in the pro-coagulant activity of the ECs, which

245 were highly susceptible to CSFV infection..$^{33}$ the inhibitory effects of APS on porcine viruses

246 infection have verified ${ }^{34}$ and APS has been observed to regulate the levels of immunomodulating

247 compounds in many different cell types. ${ }^{35,36}$ The manifestation of adhesion molecules, including

248 P-selectin and E-selectin, was inhibited by APS and persisted while the ECs were stimulated with

249 CSFV, which could promote the expression of both P- and E-selectin (Figure 2AB). Similarly, the

250 increase of TF (Figure 2D), TGF- $\beta$ (Figure 4C), and IL-8 (Figure 3F) production in response to

251 CSFV was inhibited by APS.

252 The coordinated expression of adhesion molecules leads to the localization of leukocytes to a

253 tissue or organ, and members of the selectin family initially mediate the transition from rapidly

254 flowing the bloodstream to rolling along the endothelium. ${ }^{37}$ E-selectin is an early mediator of

255 leukocyte-endothelial adhesion and is expressed on activated endothelium. ${ }^{38}$ The data presented

256 in the present study unequivocally demonstrated that APS inhibited the activation of E-selectin

257 caused by CSFV which was also delayed by APS pre-treatment, indicating that APS has a

258 preventive effect on the hemorrhaging stimulated by CSFV. However, the addition of APS

259 following infection with CSFV induced the co-stimulation of E-selectin which fade away after 3 
260 hours, indicating that the addition of APS may enhance vaccine effectiveness, but can't maintain

261 for a long time (Figure 2A).

262 Our results also revealed that VEGF expression was increased by CSFV and could be further

263 enhanced with the pre-treatment of APS (Figure 2C). This finding indicates that CSFV and APS

264 may elicit an angiogenic response via VEGF. ${ }^{10}, 39$ Furthermore, the release of TF may be

265 important in mediating the activation of both coagulation and fibrinolytic mechanisms. ${ }^{40} \mathrm{We}$

266 found that APS inhibited the expression of TF, which was upregulated by CSFV. The inhibition

267 of APS appeared later than upregulation of CSFV (Figure 2D). This phenomenon involved in

268 disseminated intravascular coagulation and thrombocytopenia during the progression of CSFV. ${ }^{2}$

269 As a pattern recognition receptor, TLR4 can activate the innate immune response to both

270 bacterial and viral pathogens, including RNA viruses. ${ }^{41}$ We demonstrated that the immune

271 response mediated by TLR4 in ECs was induced by CSFV, which contributes to the ability of

272 CSFV to replicate without exerting a cytopathic effect (CPE). ${ }^{42,}{ }^{43}$ We found that APS can inhibit

273 the expression of TLR4 in ECs following infection with CSFV (Figure 3A) at a later time, while

274 co-stimulate and promote it at an early time point, indicating that APS can regulate innate

275 immunity and vessel remodeling via TLR4 expression which has been proved in macrophages

276 lately. $^{23}$

277 The suppression of IFN- $\beta$ plays a role in the inability of porcine viruses to spread and cause

278 disease in susceptible animals; ${ }^{44}$ however, this cytokine was upregulated when the ECs were

279 pretreated with APS (Figure 3C). Our results demonstrate that CSFV inhibited the expression of

280 IFN- $\gamma$ (which always fails to be produced in cells infected with CSFV ${ }^{42}$ ). IFN- $\gamma$ profoundly

281 inhibited African swine fever virus replication in porcine macrophages, ${ }^{45}$ as well as the cytopathic 
282 effect produced by CSFV; ${ }^{46}$ however, this inhibition remained unchanged following the addition 283 of APS (Figure 4B).

284 IL-1, IL-6, and IL-8 are typical examples of the multifunctional cytokines involved in the 285 regulation of the immune response, hematopoiesis, and inflammation. ${ }^{47,}{ }^{48}$ Following an infection 286 with CSFV, there is an initial and brief increase in the transcript levels of IL-1 and $8,{ }^{42}$ which was 287 confirmed in our study (Figure 3DEF); the increase in IL-8 was inhibited by APS.

288 In conclusion, the data from the present study indicate that APS induced the production of 289 immune factors and prevented an increase in adhesion molecules, which were inhibited and 290 activated by CSFV, respectively. In some cases, the addition of APS induced the co-stimulation of

291 factors associated with CSFV, indicating that the addition of APS may enhance vaccine efficacy.

292 Thus, APS may have an modulation effect on ECs exposed to CSFV and utilize different 293 mechanisms to influence the adhesion-related immune response of ECs during the hemorrhagic 294 treatment. However, in vitro data is not sufficient to conclude that APS has a preventive effect on 295 the hemorrhaging induced by CSFV. These possibilities warrant further study to evaluate whether 296 APS may be an effective adjuvant in in vivo clinical vaccine trials against CSFV.

\section{Reference}

298 1. Paton D J, Greiser-Wilke I. Classical swine fever--an update[J]. Res Vet Sci, 2003,75(3):169-178.

299 2. Penrith M L, Vosloo W, Mather C. Classical swine fever (hog cholera): review of aspects relevant to control[J].

$300 \quad$ Transbound Emerg Dis, 2011,58(3):187-196.

301 3. Dong X Y, Liu W J, Zhao M Q, Wang J Y, Pei J J, Luo Y W, Ju C M and Chen J D. Classical swine fever virus

302 triggers RIG-I and MDA5-dependent signaling pathway to IRF-3 and NF- $\mathrm{BB}$ activation to promote secretion of

303 interferon and inflammatory cytokines in porcine alveolar macrophages[J]. Virology J, 2013, 10:286. 
304 4. Borca, M V, Gudmundsdottir I, Fernandez-Sainz I J, Holinka L G and Risatti G R. Patterns of cellular gene

305 expression in swine macrophages infected with highly virulent classical swine fever virus strain Brescia. Virus

$306 \quad$ Res, 2008, $138(1-2): 89-96$.

307 5. Sasaki N, Toyoda M. Glycoconjugates and related molecules in human vascular endothelial cells[J]. Int J Vasc

$308 \quad$ Med, 2013,2013:963596.

309 6. Ning P, Zhou Y, Liang W, Zhang Y. (2016) Different RNA splicing mechanisms contribute to diverse infective

310 outcome of classical swine fever viruses of differing virulence: insights from the deep sequencing data in swine

311 umbilical vein endothelial cells. PeerJ 4:e2113

312 7. He L, Zhang Y, Fang Y, Liang W, Lin J and Cheng M. Classical swine fever virus induces oxidative stress in

313 swine umbilical vein endothelial cells. BMC Vet Res, 2014, 10:279.

314 8. Bierhaus A, Nawroth P P. Modulation of the vascular endothelium during infection--the role of NF-kappa B

315 activation[J]. Contrib Microbiol, 2003,10:86-105.

316 9. Rosemblatt M, Bono M R. Functional consequences of immune cell adhesion to endothelial cells[J]. Curr

317 Pharm Des, 2004,10(2):109-120.

318 10. Pasyk K and Jakobczak B. Vascular endothelium: recent advances. EUR J DERMATOL,2004, $14: 209-213$.

319 11. Funayama H, Ikeda U, Takahashi M, Sakata Y, Kitagawa S, Takahashi Y, Masuyama J, Furukawa Y, Miura Y,

320 Kano S, Matsuda M and Shimada K. Human monocyte-endothelial cell interaction induces platelet-derived

321 growth factor expression. CARDIOVASC RES, 1998, 37: 216-224.

322 12. Paton DJ, Greiser-Wilke I. Classical swine fever--an update. Res Vet Sci 2003;75:169-178.

323 13. Penrith ML, Vosloo W, Mather C. Classical swine fever (hog cholera): review of aspects relevant to control.

$324 \quad$ Transbound Emerg Dis 2011;58:187-196.

325 14. Bierhaus A, Nawroth PP. Modulation of the vascular endothelium during infection--the role of NF-kappa B

326 activation. Contrib Microbiol 2003;10:86-105. 
327 15. Nishimura Y, Shimojima M, Tano Y, Miyamura T, Wakita T and Shimizu H. Human P-selectin glycoprotein 328 ligand-1 is a functional receptor for enterovirus 71[J]. Nat Med, 2009,15(7):794-797.

329 16. Rosemblatt M, Bono MR. Functional consequences of immune cell adhesion to endothelial cells. Curr Pharm 330 Des 2004;10:109-120.

331 17. Ferrara N, Davis-Smyth T. The biology of vascular endothelial growth factor. Endocr Rev 1997;18:4-25.

332 18. Ferrara N, Keyt B. Vascular endothelial growth factor: basic biology and clinical implications. EXS $333 \quad 1997 ; 79: 209-232$.

334 19. Dvorak HF, Brown LF, Detmar M and Dvorak AM. Vascular permeability factor/vascular endothelial growth 335 factor, microvascular hyperpermeability, and angiogenesis. Am J Pathol 1995;146:1029-1039.

336 20. Drake TA, Ruf W, Morrissey JH and Edgington TS. Functional tissue factor is entirely cell surface expressed on lipopolysaccharide-stimulated human blood monocytes and a constitutively tissue factor-producing neoplastic cell line. J Cell Biol 1989;109:389-395.

21. Chen R, Tan L, Jin C, Lu J, Tian L, Chang Q, Wang K. Extraction, isolation, characterization and antioxidant activity of polysaccharides from Astragalus membranaceus. Industrial Crops and Products, 2015, 77, $434-443$. nano-complexes of Astragalus polysaccharide and amphiphilic chitosan derivatives. Carbohyd Polym, 2017, 161:261-269. effects via TLR4-mediated MyD88-dependent signaling pathway in vitro and in vivo[J]. Sci Rep, 2017,; $2017,7: 44822$.

24. Jiang J, Wu C, Gao H, Song $\mathrm{J}$ and $\mathrm{Li} \mathrm{H}$. Effects of astragalus polysaccharides on immunologic function of erythrocyte in chickens infected with infectious bursa disease virus[J]. Vaccine, 2010,28(34):5614-5616.

349 25. Shao P, Zhao L H, Zhi-Chen and Pan JP. Regulation on maturation and function of dendritic cells by Astragalus 
350 mongholicus polysaccharides[J]. Int Immunopharmacol, 2006,6(7):1161-1166.

351 26. Liu Q Y, Yao Y M, Yu Y, Dong N and Sheng ZY. Astragalus polysaccharides attenuate postburn sepsis via 352 inhibiting negative immunoregulation of CD4+ CD25(high) T cells[J]. PLoS One, 2011,6(6):e19811.

353 27. Li J, Zhong Y, Li H, Zhang N, Ma W, Cheng G, Liu F, Liu F and Xu J. Enhancement of Astragalus 354 polysaccharide on the immune responses in pigs inoculated with foot-and-mouth disease virus vaccine[J]. Int $\mathrm{J}$ 355 Biol Macromol, 2011,49(3):362-368.

356 28. Zhang N, Li J, Hu Y, Cheng G, Zhu X, Liu F, Zhang Y, Liu Z and Xu J. Effects of astragalus polysaccharide on 357 the immune response to foot-and-mouth disease vaccine in mice[J]. Carbohydrate Polymers, 2010,82(3):680$358 \quad 686$

359 29. Zhang B Q, Hu S J, Qiu L H, Zhu J H, Xie X J, Sun J, Zhu Z H, Xia Q and Bian K. Effects of Astragalus 360 membranaceus and its main components on the acute phase endothelial dysfunction induced by 361 homocysteine[J]. Vascul Pharmacol, 2007,46(4):278-285.

362 30. Li S, Zhang Y, Zhao J. Preparation and suppressive effect of astragalus polysaccharide in glomerulonephritis 363 rats[J]. Int Immunopharmacol, 2007,7(1):23-28.

364 31. Wei K, Sun Z, Yan Z, Tan Y, Wang H, Zhu X, Wang X, Sheng P and Zhu R. Effects of Taishan Pinus 365 massoniana pollen polysaccharide on immune response of rabbit haemorrhagic disease tissue inactivated 366 vaccine and on production performance of Rex rabbits[J]. Vaccine, 2011,29(14):2530-2536.

367 32. Zhuge Z Y, Zhu Y H, Liu P Q, Yan X D, Yue Y, Weng X G, Zhang R, Wang J F. Effects of Astragalus 368 polysaccharide on immune responses of porcine PBMC stimulated with PRRSV or CSFV[J]. PLoS One, $3692012,7(1): \mathrm{e} 29320$.

370 33. Campos E, Revilla C, Chamorro S, Alvarez B, Ezquerra A, Domínguez J, Alonso F. In vitro effect of classical swine fever virus on a porcine aortic endothelial cell line[J]. Vet Res, 2004,35(6):625-633.

372 34. Xue H, Gan F, Qian G, Hu J, Hao S, Xu J, Chen X and Huang K. Astragalus polysaccharides attenuate PCV2 
373 infection by inhibiting endoplasmic reticulum stress in vivo and in vitro. Sci Rep, 2017, 7:40440.

374 35. Wu S, Ren X, Li Y, Guo W, Lei X, Yao J and Yang X. Effect of dietary Astragalus Polysaccharide supplements

375 on testicular miRNA expression profiles and enzymatic changes of breeder cocks. Sci Rep, $2017,7: 38864$.

376 36. Huang W, Liang Y, Tang L, Ding Y and Wang X. Antioxidant and anti-inflammatory effects of Astragalus

377 polysaccharide on EA.hy926 cells. Exp Ther Med, 2013, 6:199-203.

378 37. Lawson J A, Burns A R, Farhood A, Lynn Bajt M, Collins R G, Smith C W and Jaeschke H. Pathophysiologic

379 importance of E- and L-selectin for neutrophil-induced liver injury during endotoxemia in mice[J]. Hepatology,

$380 \quad 2000,32(5): 990-998$.

381 38. Whalen M J, Carlos T M, Kochanek P M, Clark R S, Heineman S, Schiding J K, Franicola D, Memarzadeh F,

382 Lo W, Marion D W, Dekosky S T. Neutrophils do not mediate blood-brain barrier permeability early after

383 controlled cortical impact in rats[J]. J Neurotrauma, 1999,16(7):583-594.

384 39. Ferrara N, Keyt B. Vascular endothelial growth factor: basic biology and clinical implications[J]. EXS,

$385 \quad 1997,79: 209-232$.

386 40. Levi M, Ten C H, Bauer K A, van der Poll T, Edgington TS, Büller HR, van Deventer SJ, Hack CE, ten Cate

387 JW, Rosenberg RD. Inhibition of endotoxin-induced activation of coagulation and fibrinolysis by pentoxifylline

388 or by a monoclonal anti-tissue factor antibody in chimpanzees[J]. J Clin Invest, 1994,93(1):114-120.

389 41. Rassa J C, Meyers J L, Zhang Y, Kudaravalli R, Ross SR. Murine retroviruses activate B cells via interaction

390 with toll-like receptor 4[J]. Proc Natl Acad Sci U S A, 2002,99(4):2281-2286.

391 42. Bensaude E, Turner J L, Wakeley P R, Sweetman DA, Pardieu C, Drew TW, Wileman T, Powell PP. Classical

392 swine fever virus induces proinflammatory cytokines and tissue factor expression and inhibits apoptosis and

393 interferon synthesis during the establishment of long-term infection of porcine vascular endothelial cells[J]. $\mathrm{J}$

394 Gen Virol, 2004,85(Pt 4):1029-1037.

395 43. Jiang H, Wang P Z, Zhang Y, Xu Z, Sun L, Wang LM, Huang CX, Lian JQ, Jia ZS, Li ZD, Bai XF. Hantaan 
396 virus induces toll-like receptor 4 expression, leading to enhanced production of beta interferon, interleukin-6

397 and tumor necrosis factor-alpha[J]. Virology, 2008,380(1):52-59.

398 44. Chinsangaram J, Piccone M E, Grubman M J. Ability of foot-and-mouth disease virus to form plaques in cell

399 culture is associated with suppression of alpha/beta interferon[J]. J Virol, 1999,73(12):9891-9898.

400 45. Esparza I, Gonzalez J C, Vinuela E. Effect of interferon-alpha, interferon-gamma and tumour necrosis factor on

401 African swine fever virus replication in porcine monocytes and macrophages[J]. J Gen Virol, 1988,69 ( Pt

402 12):2973-2980

403

46. Xia C, Dan W, Wen-Xue W, Jian-Qing W, Li W, Tian-Yao Y, Qin W, Yi-Bao N. Cloning and expression of interferon-alpha/gamma from a domestic porcine breed and its effect on classical swine fever virus[J]. Vet Immunol Immunopathol, 2005,104(1-2):81-89.

47. Molbak K, Lisse I M, Aaby P. T-lymphocyte subsets and prolonged diarrhea in young children from GuineaBissau[J]. Am J Epidemiol, 1996,143(1):79-84. rotavirus shedding in the absence of interleukin-6: Th1 cells and immunoglobulin A develop normally[J]. $\mathrm{J}$ Virol, 2000,74(11):5250-5256.

49. Zhu Y, Magnusson U, Fossum C, Berg M. Escherichia coli inoculation of porcine mammary glands affects local mRNA expression of Toll-like receptors and regulatory cytokines[J]. Vet Immunol Immunopathol, 2008,125(12):182-189.

50. Massaguer A, Engel P, Tovar V, March S, Rigol M, Solanes N, Bosch J, Pizcueta P. Characterization of platelet and soluble-porcine P-selectin (CD62P)[J]. Vet Immunol Immunopathol, 2003,96(3-4):169-181.

416 51. Liu C H, Chaung H C, Chang H L, Peng YT, Chung WB. Expression of Toll-like receptor mRNA and cytokines in pigs infected with porcine reproductive and respiratory syndrome virus[J]. Vet Microbiol, 2009,136(3- 
419 Figure Legends

420 Figure 1. ECs infected with CSFV titrated by indirect immunofluorescence. The deep brown

421 in the cells indicates which parts were infected with CSFV.

422 Figure 2. The relative mRNA expression of P-selectin (A), E-selectin (B), VEGF (C) and TF

423 (D) in porcine ECs. The relative mRNA expression in porcine ECs cultured with either medium 424 alone (Medium), pretreated with APS (APS pre-treated), APS, CSFV, CSFV following 425 pretreatment with APS (CSFV+APS pre-treated), or CSFV plus APS (CSFV+APS). Different 426 texture filled in bars shows different culture conditions which illustrated in A. Gene expression 427 was analyzed by SYBE Green RT-PCR. Data are presented as the means \pm SEM of three 428 independent experiments. Within the same time point: *, $P<0.05 ; * *, P<0.01 ; * * *, P<0.001$.

429 Figure 3. Relative mRNA expression of TLR4 (A), IFN- $\alpha$ (B), IFN- $\beta$ (C), IL-1 (D), IL-6 (E)

430 and IL-8 (F) in porcine ECs. Relative mRNA expression in porcine ECs cultured with either 431 medium alone (Medium), pretreatment with APS (APS pre-treated), APS, CSFV, CSFV 432 following pretreatment with APS (CSFV+APS pre-treated), or CSFV plus APS (CSFV+APS). 433 Different texture filled in bars shows different culture conditions which illustrated in A. Gene 434 expression was analyzed by SYBE Green RT-PCR. Data are presented as the mean \pm SEM of 435 three independent experiments. Within the same time point: ${ }^{*}, P<0.05 ; * *, P<0.01 ; * * *, P<$ $436 \quad 0.001$.

Figure 4. Enzyme-linked immunosorbent assay of IFN- $\alpha$, IFN- $\gamma$ and TGF- $\beta$ in cell culture supernatants. Porcine ECs were cultured with either medium alone (Medium), pretreated with

439 APS (APS pre-treated), APS, CSFV, CSFV following pretreatment with APS (CSFV+APS pre440 treated), or CSFV plus APS (CSFV+APS). Data are presented as the means \pm SEM of three 
441 independent experiments. Comparisons between all groups $P<0.001$. 
443 Table 1. Sequences of the oligonucleotide primers used for real-time RT-PCR.

444

\begin{tabular}{|c|c|c|}
\hline $\begin{array}{l}\text { Gene } \\
\text { specificity }\end{array}$ & & Oligonucleotide sequences $\left(5^{\prime}-3^{\prime}\right)$ of primers \\
\hline \multirow[t]{2}{*}{ HPRT $^{\mathrm{a}}$} & $\mathrm{F}$ & GTGATAGATCCATTCCTATGACTGTAGA \\
\hline & $\mathrm{R}$ & TGAGAGATCATCTCCACCAATTACTT \\
\hline \multirow[t]{2}{*}{ P-selectin ${ }^{\mathrm{b}}$} & $\mathrm{F}$ & AACGGAGGGGAGGCAACAAGAC \\
\hline & $\mathrm{R}$ & GTGAGGGGACCAAGAGAAG \\
\hline \multirow[t]{2}{*}{ E-selectin ${ }^{\mathrm{b}}$} & $\mathrm{F}$ & ATGATTGCTTCACAGTTTCTCT \\
\hline & $\mathrm{R}$ & TCACATGTCACAGCTTTACACG \\
\hline \multirow[t]{2}{*}{ TLR-4 ${ }^{c}$} & $\mathrm{~F}$ & AAGGTTATTGTCGTGGTGT \\
\hline & $\mathrm{R}$ & CTGCTGAGAAGGCGATAC \\
\hline \multirow[t]{2}{*}{ VEGF $^{\mathrm{d}}$} & $\mathrm{F}$ & ATGAACTTTCTGCTGTCTTGGGTG \\
\hline & $\mathrm{R}$ & TCACCGCCTCGGCTTGTCACATCT \\
\hline \multirow[t]{2}{*}{$\mathrm{TF}^{\mathrm{d}}$} & $\mathrm{F}$ & TTCAAGAC ( A/C) ATT ( T/C) TGGAGTGG \\
\hline & $\mathrm{R}$ & AGGGGGAGTTGGTAAAC \\
\hline \multirow[t]{2}{*}{${\mathrm{IL}-1^{\mathrm{d}}}^{\mathrm{L}}$} & $\mathrm{F}$ & ACTTCCTGGGGACGGCATGGATAAA \\
\hline & $\mathrm{R}$ & GCATCATTCAGGATGCACTGGTGGT \\
\hline \multirow[t]{2}{*}{${\mathrm{IL}-6^{\mathrm{d}}}^{\mathrm{d}}$} & $\mathrm{F}$ & GCTGCTTCTGGTGATGGCTACTGCC \\
\hline & $\mathrm{R}$ & TGAAACTCCACAAGACCGGTGGTGA \\
\hline \multirow[t]{2}{*}{${\mathrm{IL}-8^{\mathrm{d}}}^{2}$} & $\mathrm{~F}$ & AGCCCGTGTCAACATGACTTCC \\
\hline & $\mathrm{R}$ & GAATTGTGTTGGCATCTTTACTGA \\
\hline \multirow[t]{2}{*}{ IFN- $\alpha^{\mathrm{d}}$} & $\mathrm{F}$ & ATGGCCCCAACCTCAGCCTTC \\
\hline & $\mathrm{R}$ & TCACTCCTTCTTCCTGAGTCT \\
\hline \multirow[t]{2}{*}{ IFN- $\beta^{\mathrm{d}}$} & $\mathrm{F}$ & ATGGCTAACAAGTGCATCCTCCAA \\
\hline & $\mathrm{R}$ & TCAGTTCCGGAGGTAATCTGTAAG \\
\hline
\end{tabular}

445

446 HPRT, hypoxanthine phosphoribosyl-transferase; IFN- $\alpha$, interferon $\alpha$; IL-1, interleukin 1; F, forward primer; R, reverse primer.

$447 \quad \mathrm{a} ;{ }^{49} \mathrm{~b} ;{ }^{50} \mathrm{c} ;{ }^{51} \mathrm{~d} .{ }^{42}$ 
Figure 1

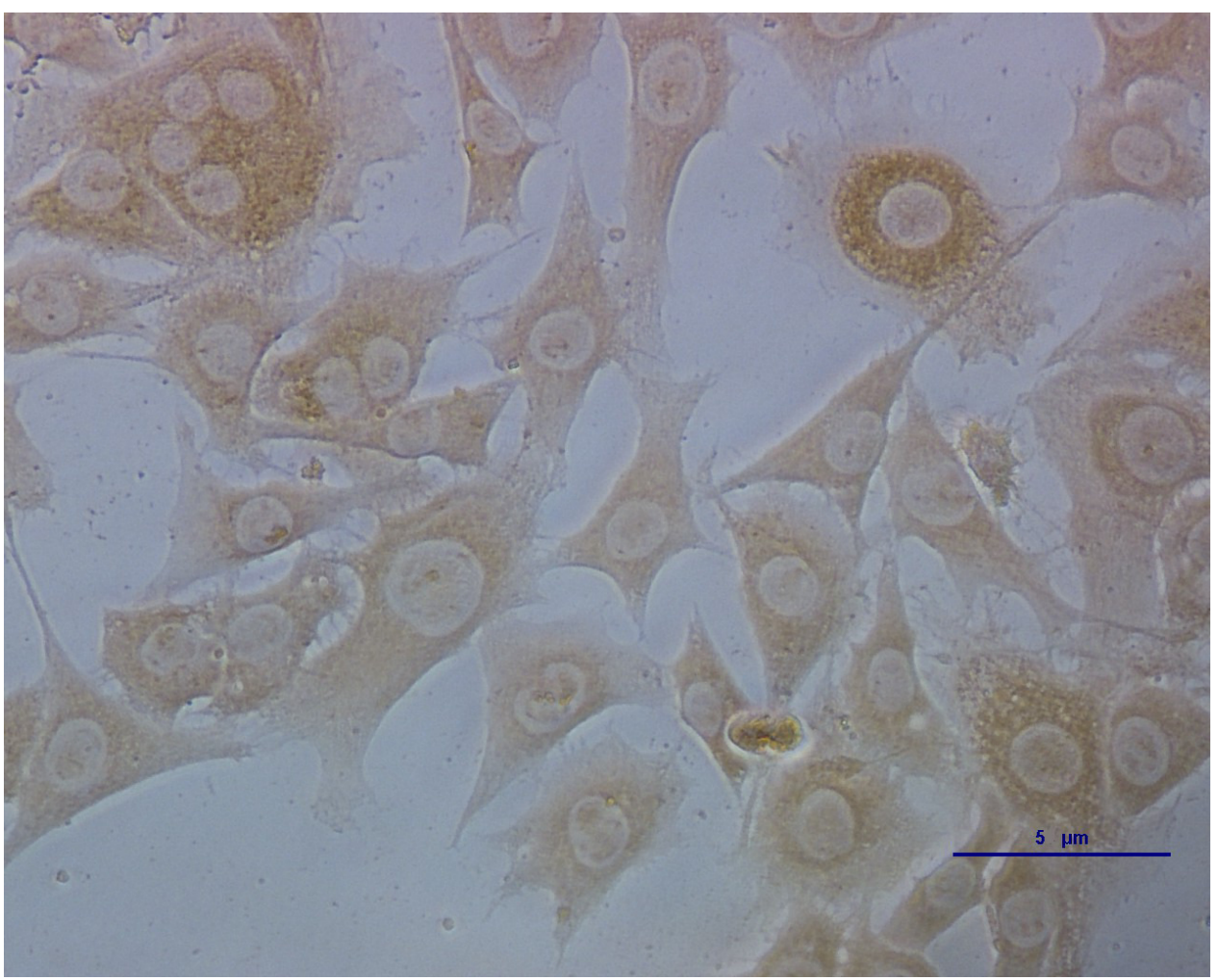

Figure 2
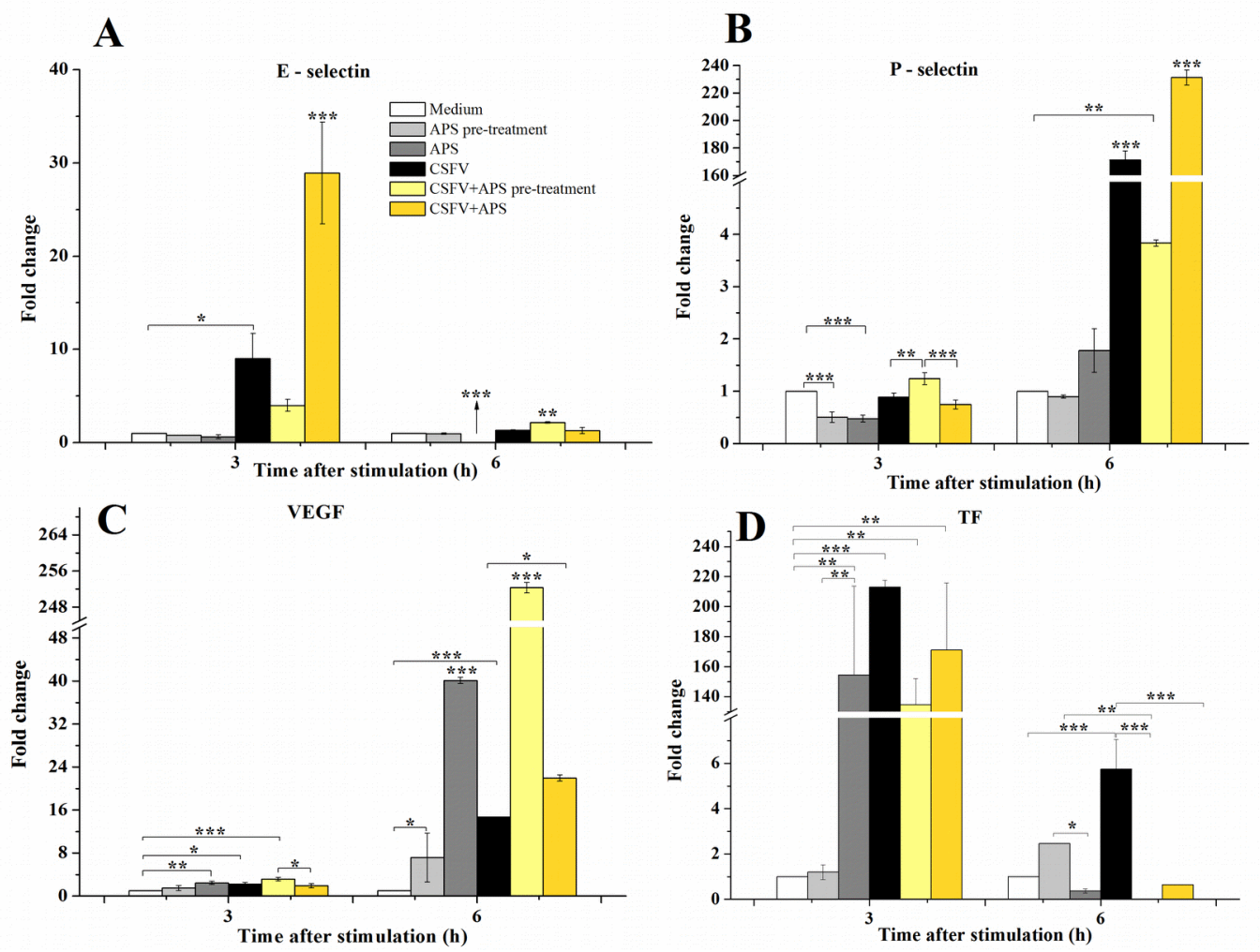
453 Figure 3
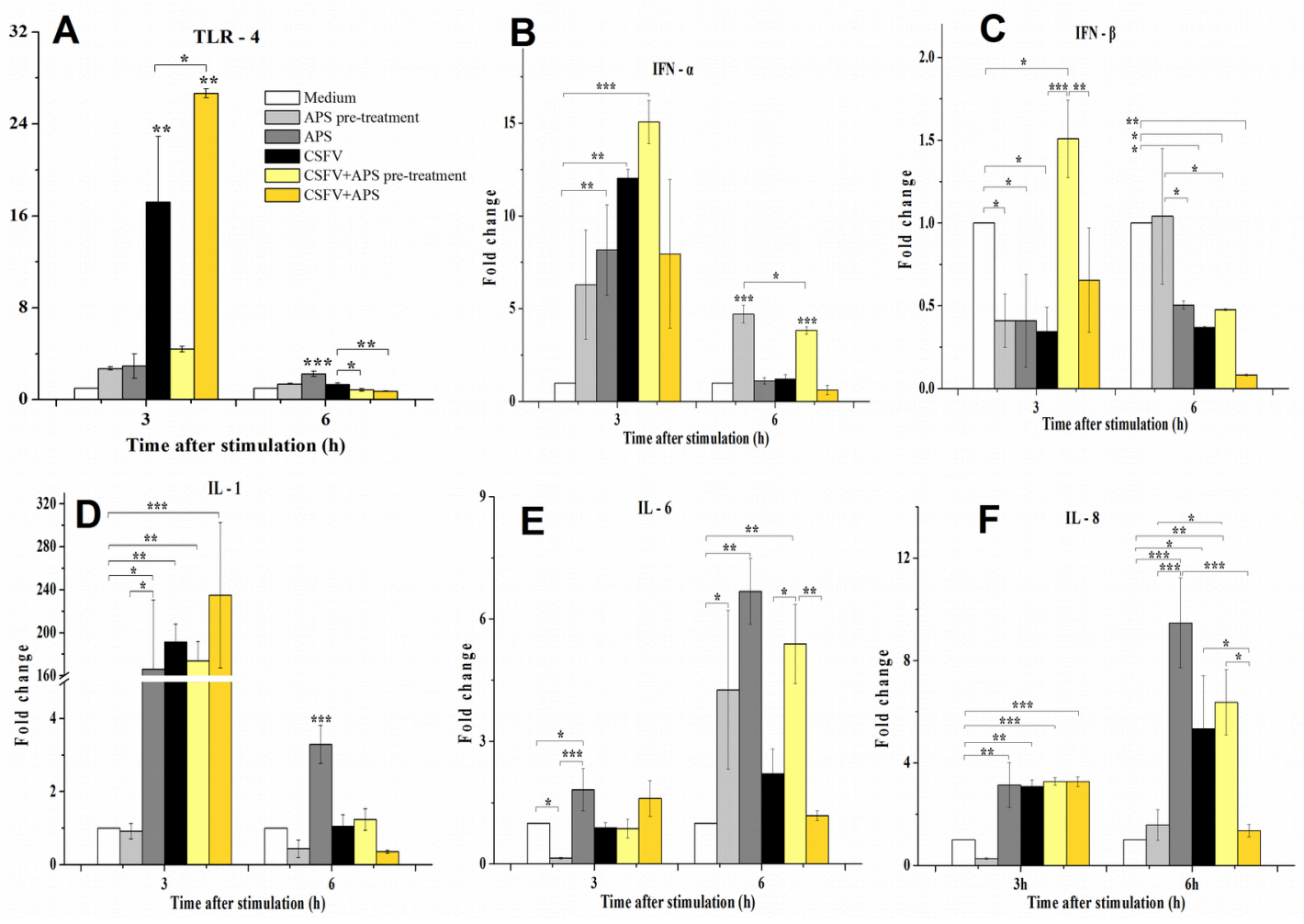

Figure 4 

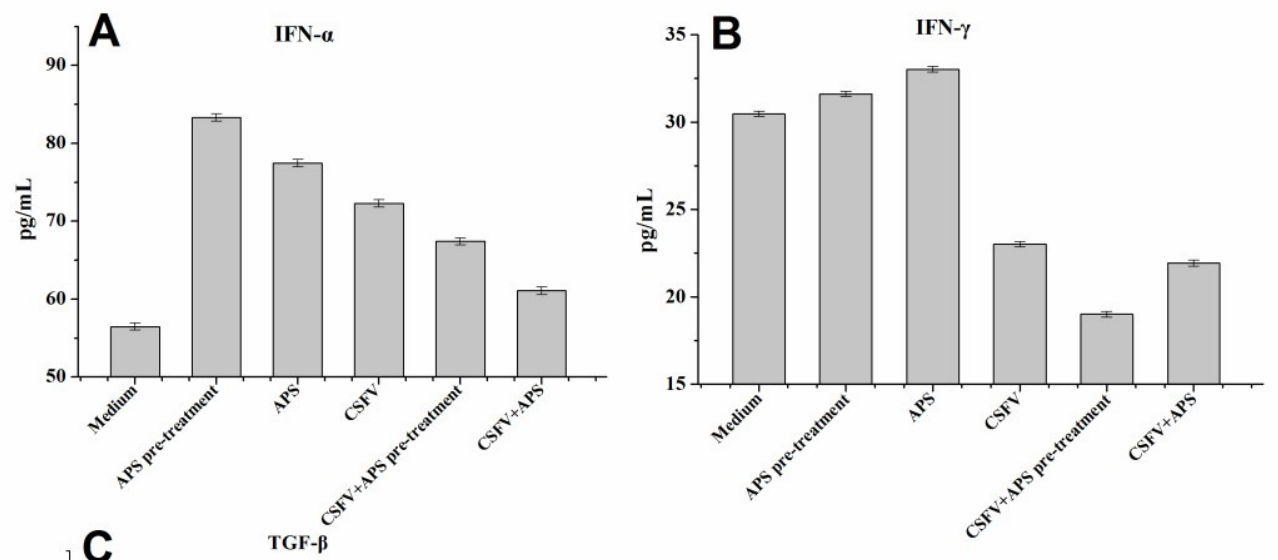

456

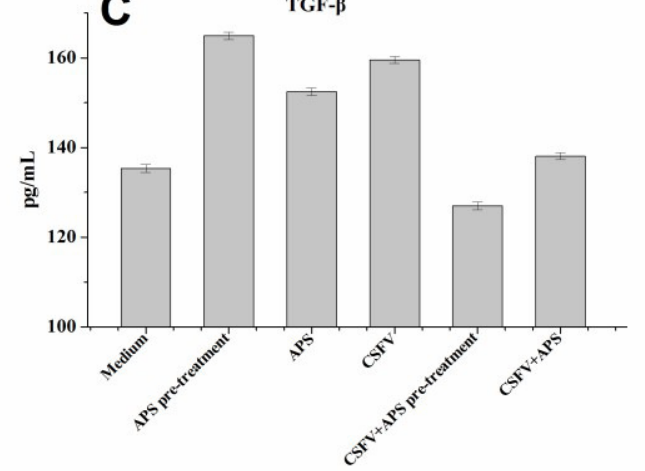

